VARIA 



\title{
LO IMAGINARIO: UN POSIBLE ACERCAMIENTO ENTRE BACHELARD Y CASTORIADIS
}

\author{
Jeannette Campos Salas
}

\begin{abstract}
RESUMEN
En este artículo, se establecen algunos paralelismos entre la concepción de lo imaginario en Gastón Bachelard con el imaginario como creación en el dominio histórico-social de Cornelius Castoriadis. Asimismo, se analiza la ontología de la imagen creadora en Bachelard en relación con la ontología del fenómeno social en Castoriadis.

Palabras clave: imaginario social, imaginario poético, imagen creadora, creación, fenómeno social, ontología.
\end{abstract}

\begin{abstract}
This article stablishes some paralelisms beetwen the conception of the imaginary in Gastón Bachelard with the imaginary like creation in the social-historic domain of Cornelius Castoriadis. In same way it analizes the ontology of the creative image in Bachelard and the ontology of the social phenomenon in Castoriadis.

Key words: social imaginary, poetic imaginary, creative image, creation, social phenomenon, ontology.
\end{abstract}

\section{La ontología de la imagen creadora en Gastón Bachelard}

Gastón Bachelard (1965a; 1965b) estudia desde el punto de vista psicológico y filosófico la gran significación que tienen los espacios del ensueño poético y el poder que genera la imaginación creadora en otras almas. Dicho autor sostiene que la imagen poética (creadora) no tiene pasado. Se plantea como indispensable la novedad de la imagen. Hay una dinámica inmediata de la imagen que le permite estar siempre renovándose.

Lic. Jeannette Campos Salas. Profesora. Escuela de Estudios Generales. Universidad de Costa Rica.

Correo electrónico: jeancampos2001@yahoo.com

Recepción: 27- 07- 2011

Aceptación: 26- 09- 2011 
La relación: imagen-poética, arquetipo-dormido no es causal y de esta manera plantea Bachelard la existencia de una imaginación trascendental que estaría constituida por arquetipos primigenios capaces de activar todo un mundo cargado de símbolos. Así, como lo entiende Bachelard, lo imaginario es ese poder específico de la conciencia que libera al ser humano de las imágenes primeras y perceptivas.

El psicólogo suizo Carl Gustav Jung (1974) inaugura el estudio de un nuevo estrato que no había sido ni fue aceptado por Freud. Este es el inconsciente colectivo, estadio psíquico que arraiga una memoria ahistórica y colectiva. Bachelard parece verse atraído por este planteamiento jungiano que cae casi en lo esotérico y considera que la conciencia humana posee un conjunto de estructuras dinámicas que pueden vibrar frente a lo nuevo de algo muy viejo que estaba en el interior mismo de esa conciencia dormida.

El arquetipo es considerado una tendencia permanente de la psique humana a engendrar imágenes que constituyen los elementos fundamentales de toda manifestación del alma humana; de modo que el arquetipo como tal no puede ser representado, ya que es una estructura originaria que sólo puede ser aprehendida por el intermedio de las imágenes que derivan de él. En la imagen poética, según Bachelard, resuenan los ecos del pasado.

La imagen creadora para Bachelard escapa de la causalidad como fenómeno indispensable para la investigación. En el desarrollo del concepto de imaginación creadora, se insiste en la tesis de su carácter primitivo, es decir, que nada la antecede; por eso, se afirma que no tiene pasado. Se plantea de esta manera una ontología directa de la imagen poética, ya que esta adquiere su propio ser: el ser de la imagen.

La resonancia y la repercusión enfatizan sobre este fenómeno de la no causalidad de la imagen creadora. Además, fundan la posibilidad de la intersubjetividad. La resonancia y la repercusión marcan la pauta para percibir la sonoridad de ser: "En la resonancia oímos el poema, en la repercusión lo hablamos" (Bachelard 1965a: 14).

La repercusión instaura un cambio de ser. La imagen creadora logra reanimar en nosotros algunas profundidades de la exuberancia de la psique. La imagen creadora, de esta manera, toca primero las profundidades y luego conmueve las superficies. Según Bachelard, el poeta logra activar una tonalidad en el lector apasionado. Este tiene la impresión de que él mismo hubiera podido crear esa imagen o de que debería haberla creado. La imagen poética se hace nuestra y echa raíces en nosotros mismos. Es por esta actividad propiciada por la dinámica inmediata de la imagen que Bachelard afirma: "la imagen poética tendrá sonoridad de ser. El poeta habla en el umbral del ser" (1965b: 8). La imagen poética se arraiga en mi ser. Se da una comunicación entre una imagen singular que cobra ser y mi ser. He aquí el significado ontológico de la imagen poética en Bachelard: su resonancia.

La imagen debe vibrar en mi ser de forma tal que mi alma pueda sentir que esa percepción provocada por el texto poético se ha anticipado a algo que tenía dentro y que no había podido hacer sonar. Es la experiencia de una "comunión" la que se plantea aquí, y es llevada por Bachelard a una fenomenología de la imaginación. Es decir, esta resonancia de almas bachelardianas propicia el estudio del fenómeno de la imagen poética como un "producto directo del corazón, del alma, del ser del hombre captado en su actualidad” (1965b: 9).

Para entender esta metafísica de la imaginación planteada por Bachelard, hay que remitirse a la trans-subjetividad de la imagen poética, despojarse de los "hábitos intelectuales" para que una imagen, a veces muy singular, logre aparecer como concentración de todo el psiquismo. ¿Cómo -se pregunta Bachelard- la aparición de una imagen poética puede hacer 
reaccionar o resonar otras almas y otros corazones? "pese a todos los prudentes pensamientos complacidos en su inmovilidad?” (Bachelard 1965a: 10). Debe recordarse aquí que la imagen poética es variable y no constitutiva como el concepto. No se toma como si fuera un objeto, la imagen está antes que el pensamiento.

Sólo la fenomenología - responde Bachelard- es decir, sólo la consideración del "surgir" de la imagen en una conciencia individual puede ayudar a comprender y medir toda la amplitud y fuerza de la trans-subjetividad de la imagen poética: "Se pide al lector de poemas que no tome una imagen como un objeto, menos aún como un sustituto de objeto, sino que capte su realidad específica" (1965a: 10).

Para lograr esto, se ha de asociar a la conciencia con su "producto más fugaz", es decir, con la imagen poética. Este producto fugaz de la conciencia, esa unión por la imagen de una "subjetividad pura pero efímera" con la realidad es para el fenomenólogo un amplio campo de experiencias. La imagen poética es simple y en su simplicidad no necesita un saber. Es propiedad de una conciencia ingenua.

Con el fin de aclarar más aún que la imagen es antes que el pensamiento, Bachelard agrega: "[...] en su expresión (la imagen) es lenguaje joven. El poeta en la novedad de sus imágenes es siempre origen del lenguaje" (1965a: 11). De esta manera, la fenomenología de la imagen bachelardiana es una fenomenología del alma, de la conciencia soñadora. El tono poético que corresponde al alma debe quedar "abierto a nuestras investigaciones fenomenológicas" (1965b: 12).

La profundidad ontológica de la imagen poética en Bachelard radica en este rompimiento de antemano con todos los hábitos de la investigación filosófica que presuponen siempre la causalidad: "Considerada en la transmisión de un alma a otra, se ve que una imagen poética elude las investigaciones de causalidad” (Bachelard 1965b: 16).

Así, la novedad de la imagen poética explicada aquí plantea el problema de la creación del ser que habla, del ser que da origen a una diversidad de imágenes poéticas y logra, de esta manera, abrir camino al estudio de la imaginación y del imaginario.

\section{Lo imaginario: la creación en el dominio histórico-social}

En el libro Los Dominios del hombre, específicamente en su apartado acerca de Lo imaginario como creación en el dominio histórico-social, Cornelius Castoriadis (1989) aborda una crítica a la ontología tradicional de occidente, pues considera que esta reduce el mundo, las cosas, los sujetos, a partir de una hiper-categoría: la determinación. Esto es algo que él observa tanto en la filosofía clásica griega como en el idealismo alemán y posteriormente en la ciencia moderna. Sería un rasgo común a toda la ontología tradicional occidental. El problema de este planteamiento es que lleva a negar el tiempo y en última instancia, el cambio:

\footnotetext{
La determinación -dice Castoriadis- lleva a la a-temporalidad: Si algo está verdaderamente determinado lo está desde siempre y para siempre. Si cambia, los modos de su cambio y las formas que ese cambio puede producir ya están determinados. Los sucesos no son pues más que la realización de las leyes, y la historia no es más que el despliegue... de una sucesión que sólo es simple coexistencia para un espíritu absoluto. (Castoriadis 1988: 65)
}

Según Castoriadis, la ontología tradicional reduce el mundo a 3 categorías: primera, sustancias o cosas; segunda, sujetos y tercera, conceptos o ideas, así como todas las posibles combinaciones entre ellas. Esta es la manera en que la ontología tradicional interpreta el 
mundo. Castoriadis se propone a elaborar una crítica ontológica hacia este determinismo, con el fin de plantear una Ontología Social de lo Indeterminado. Para esto, recurre a la categoría de lo Imaginario. Castoriadis afirma que la sociedad es una Forma:

\footnotetext{
El hombre solo existe en la sociedad y por la sociedad...y la sociedad es siempre histórica. La sociedad como tal es una forma, y cada sociedad dada es una forma particular y singular. La forma implica la organización, en otras palabras, el orden (o, si se prefiere, el orden/desorden). (Castoriadis 1988: 66)
}

¿Qué es una forma y cómo surge la forma? se pregunta Castoriadis. Una forma es, pues, organización, orden y esta se da o surge dentro del dominio de lo histórico-social. Para dar un sentido a esta afirmación, nos hemos de preguntar primero ¿Qué mantiene unida a una sociedad? y segundo, ¿Qué hace nacer nuevas formas de sociedad?

\footnotetext{
Lo que mantiene a una sociedad unida es su institución, el complejo total de sus instituciones particulares, lo que yo llamo la: institución de la sociedad como un todo.... aquí la palabra institución está empleada en su sentido más amplio y radical, pues significa normas, valores, lenguaje, herramientas, procedimientos y métodos de hacer frente a las cosas y de hacer cosas y, desde luego, el individuo mismo. (Castoriadis 1988: 67)
}

Pero podemos ir más allá y preguntarnos, ¿en qué consiste la unidad de la institución? Castoriadis nos dice que esa unidad se apoya en la cohesión interna de una compleja red o urdimbre de significaciones, que son las que "empapan, orientan y dirigen toda la vida de la sociedad y a los individuos concretos que corporalmente la constituyen" (Castoriadis 1988: 68). Esta red de significaciones es lo que él llama lo imaginario y su cohesión interna es lo que hace que una sociedad siga siendo esa misma sociedad a través de los cambios. Esto hasta que no se dé un cambio en su forma.

Esas significaciones son imaginarias porque "no corresponden a elementos racionales o reales y no quedan agotadas por referencia a dichos elementos, sino que están dadas por creación" (Castoriadis 1988: 68). Y son sociales porque: "Sólo existen estando instituidas y siendo objeto de participación de un ente colectivo impersonal y anónimo" (Castoriadis 1988: 68).

La forma que adquiere una sociedad es su Imaginario Social:

\footnotetext{
La institución de la sociedad es lo que determina aquello que es real y aquello que no lo es, lo que tiene un sentido y lo que carece de sentido...Toda sociedad es un sistema de interpretación del mundo...toda sociedad es una construcción, una constitución, creación de un mundo, de su propio mundo. Su propia identidad no es otra cosa que ese sistema de interpretación, ese mundo que ella crea. (Castoriadis 1988: 69)
}

Lo imaginario no es, pues, una creación individual o de sujetos e individuos: es una creación colectiva, y lo que mantiene unida a la sociedad es su Institución. Pero ¿cuál sería la parte de nuestro pensamiento que no está condicionada, determinada, por la institución? Castoriadis la busca en la dimensión imaginaria, y por tanto creadora, en el dominio histórico-social.

\footnotetext{
Las operaciones lógicas y físicas por las cuales toda sociedad se remite al primer estado natural, lo organiza y lo utiliza, están siempre sujetas a significaciones imaginarias sociales que son arbitrarias y radicalmente diferentes en las distintas sociedades. (Castoriadis 1988: 71)
}

Es en el terreno de lo imaginario social donde podemos reconocer los cambios de la forma; como se puede observar en el paso del mito al logos en la sociedad griega, o del feudalismo al capitalismo en las sociedades europeas. Castoriadis explora en esta dimensión imaginaria la posibilidad de una ontología histórico-social de lo indeterminado. Se podría decir que el teórico va más allá de la interpretación tradicional del mundo y toma en cuenta la concepción del contenido de la psique social. 
La institución de la sociedad y sus significaciones imaginarias se despliegan, según Castoriadis, en dos dimensiones indisociables: una dimensión lógica ("conjuntistaidentitaria") y una dimensión imaginaria. En la dimensión lógica, el principio que opera es el de la determinación, entendiendo a esta como la búsqueda de elementos, clases, propiedades y relaciones típicas de las ciencias lógico-formales: "desde el punto de vista de esta dimensión, la existencia es la determinación" (Castoriadis 1988: 71). En cambio, en la dimensión imaginaria opera el principio de la remisión: "toda significación remite a un número indefinido de otras significaciones" (Castoriadis 1988: 71). Se remiten unas a otras y crean un tipo de organización magmática (fluido, o ebullición en cambio perpetuo). Aquí, la existencia es significación, afirma Castoriadis. De esta forma, la relación entre el signo y aquello de lo que el signo es signo, es decir, su significado, (lo que Castoriadis llama la relación signitiva) es indeterminada, "arbitraria", aleatoria, está sometida a la aleatoriedad de lo instituido.

\footnotetext{
El orden y la organización sociales no pueden reducirse a los conceptos habituales del orden y de la organización en matemática, en física y hasta en biología. Lo histórico social crea un tipo ontológico de nuevo orden (de unidad, de cohesión y de diferenciación organizada)...Ese tipo ontológico es cada vez materializado por medio de otras formas, cada una de las cuales representa una creación, un nuevo eidos de sociedad. (Castoriadis 1988: 72-73)
}

Castoriadis quiere, en última instancia, elaborar una ontología social materialista pero no determinista, siempre sometida al cambio. Lo que crea nuevas formas de orden se da, pues, en lo histórico social.

Podemos ver otros cambios de formas de sociedad en el paso del orden medieval al orden moderno, por ejemplo. Lo histórico social como creación, como producción es indeterminado. La ontología tradicional ha sido incapaz de captar el ser propio de lo histórico social. La creación es el modo de ser del campo histórico social.

Para Castoriadis, en lugar de preguntarnos por las causas, los sujetos o las sustancias, habría que preguntarse más bien "cómo lo antiguo entra en lo nuevo con la significación que lo nuevo le da" (1988: 74). La sociedad es auto-creación que se despliega como historia; reconocer esto requiere una conversión ontológica radical. Castoriadis se pregunta entonces, cómo emergen formas histórico sociales nuevas: por creación - responde.

Pero se trata de una dinámica de cambio que podemos como máximo dilucidar, no explicar, en el sentido de reducirla a una serie de principios elementales o primarios. Así, por ejemplo, la aparición de la modernidad capitalista se presenta para Castoriadis como el surgimiento de una nueva significación imaginaria social: la expansión ilimitada del dominio racional. Existe, a pesar de todo, una cierta permanencia en el cambio, algo que se arrastra desde lo anterior. La aparición de una nueva forma histórico-social no es fruto de la voluntad predeterminada de sus actores o circunstancias ni de una combinación aleatoria, sino de la inserción de los elementos y factores del viejo orden en el nuevo, de una manera que sea útil o aprovechable por este último, lo que les aporta un nuevo sentido. Por ejemplo, el estado dinástico y el estado capitalista, para garantizar las condiciones de reproducción del capitalismo.

Esta dinámica abierta de cambio es lo que define, para Castoriadis, la autonomía en el dominio histórico-social. Esta posibilidad de autonomía, que se dio por primera vez en la antigua Grecia y luego, de nuevo, en Europa Occidental al final de la Edad Media, supuso una ruptura histórica sin precedentes: 


\begin{abstract}
Por primera vez en la historia de la humanidad, de la vida y, que sepamos, del universo, nos encontramos en presencia de un ser que pone abiertamente en tela de juicio su propia ley de existencia, su propio orden dado... La creación de la democracia y la filosofía rompen el cerco de la sociedad instituida que prevalecía hasta entonces... La autonomía toma aquí el sentido de una auto-institución de la sociedad: nosotros hacemos las leyes, lo sabemos y somos, pues, responsables de nuestras leyes... Esto implica también la aparición de un individuo autónomo que puede preguntarse y también preguntar en voz alta: ¿es justa esta ley? (Castoriadis 1988: 77)
\end{abstract}

El reconocimiento de esa autonomía histórico-social de lo imaginario, entendida como apertura o indeterminación ontológica, es lo que abre para Castoriadis la posibilidad de una acción política dirigida a establecer una nueva institución de la sociedad, es decir, el cambio.

El imaginario social viene a caracterizar las sociedades humanas como creación ontológica de un modo de ser sui generis. Designa, también, al mundo singular una y otra vez creado por una sociedad como su propio mundo. El imaginario social es un "magma de significaciones imaginarias sociales" encarnadas en instituciones. Como tal, regula el decir y orienta la acción de los miembros de esa sociedad, en la que determina tanto las maneras de sentir y desear como las maneras de pensar. En definitiva, ese mundo es esencialmente histórico. Toda sociedad contiene en sí misma una potencia de alteridad. Siempre existe en un doble modo: el modo de "lo instituido", estabilización relativa de un conjunto de instituciones, y el modo de "lo instituyente”, la dinámica que impulsa su transformación.

Hay, pues, una institución imaginaria de la sociedad ¿Pero cuál es precisamente el significado de esa enigmática expresión? ¿Cómo entenderla de forma que no quede reducida a una declaración descaradamente idealista? Habría que considerar los tres términos que la forman:

a) Institución. Decir que la sociedad es instituida significa que no ha sido producida "naturalmente", es decir, que es resultado de la acción humana. La acción propiamente humana implica una intención, mediatizada por un sistema simbólico, lo que la convierte en un proyecto, irreductible a cualquier comportamiento. En tanto que su inteligibilidad remite, más que a causas, a razones.

b) Imaginario. Decir que dicha institución es imaginaria significa, en primer lugar, que es un fenómeno del espíritu y, en segundo lugar, que las significaciones y valores que orientan la sociedad son una invención de los seres humanos. Tienen que ser puestas en relación con una capacidad de creación. Las significaciones sociales, por lo tanto, no son naturales ni (completamente) racionales.

c) Sociedad/social. Decir que el imaginario es social significa que constituye un orden de fenómenos sui generis, irreducible a lo psíquico y a lo individual. El imaginario aquí invocado no es la imaginación psicológica. A la pregunta ¿quién instituye la sociedad? se da una respuesta auténticamente sociológica: no es obra de un individuo en particular, jefe o legislador, ni de un conjunto contractual de individuos; es obra de un colectivo anónimo e indivisible, que trasciende a los individuos y se impone a ellos. El imaginario social provee a la psique de significaciones y valores, y a los individuos les da los medios para comunicarse y les dota de las formas de la cooperación.

Entonces, ¿qué es una sociedad? ¿cómo se mantiene unida? Castoriadis responderá: una sociedad es un conjunto de significaciones imaginarias sociales encarnadas en instituciones a las que animan. Las significaciones, que introducen en esto la dimensión simbólica, son 
calificadas como imaginarias, pero, según Castoriadis, el imaginario como potencia de instituir y alterar es anterior a lo simbólico.

Castoriadis concibe los fenómenos sociales e históricos a partir del espíritu humano. Sociedad e historia son principalmente fenómenos de sentido. Coloca, así, la potencia creadora de las sociedades (o de los pueblos), ya no solamente la de individuos excepcionales, en el corazón de las realidades culturales e históricas. Bajo la expresión de imaginario radical pone en relieve la potencia de creación de formas sociales activas en el ámbito de lo social-histórico. De esa forma, logra poner el acento sobre aquello que separa las diversas sociedades, sobre la irreducible alteridad de sus mundos respectivos y sobre la ruptura por la cual una sociedad, en el tiempo y por el tiempo, se convierte en una nueva sociedad.

Para Castoriadis, el imaginario es el propio elemento en el cual y por el cual se despliega lo histórico-social. No se opone a lo real, sino a lo racional. Toda su ontología de lo social-histórico converge hacia una crítica del principio de determinación. La realidad humana no está nunca completamente determinada, sino que siempre se entretejen dos dimensiones: una racional, otra imaginaria. Este carácter fragmentario de la racionalidad se expresa muy particularmente en la psique y en lo social-histórico. Al desarrollar su ontología de lo socialhistórico, Castoriadis se ha visto conducido a criticar la ontología y la lógica tradicionales, que, según él, dominadas por la categoría de determinación, serían incapaces de pensar el modo propio de ser de dichos entes.

Para Castoriadis, la creación imaginaria brota primero espontáneamente del ámbito de lo social-histórico, antes de ser recuperada o pensada explícitamente.

\section{Paralelismos entre Bachelard y Castoriadis}

Gastón Bachelard comparte suelo y época con Castoriadis, pero no aparece en su lectura histórica. Bachelard otorga a lo imaginario un peso similar al que le da Castoriadis. Se podría decir que, en algunos aspectos, Castoriadis y Bachelard coinciden en la manera de exponer su ontología del fenómeno social y la ontología de la imagen creadora, respectivamente.

Para Bachelard (1965b), lo imaginario es ese poder específico de la conciencia que libera al ser humano de las imágenes primeras y perceptivas, y, como vimos anteriormente, para Castoriadis (1988) la unidad de la institución se apoya en la cohesión interna de una compleja red o urdimbre de significaciones. Esta red de significaciones es lo que él llama lo imaginario. La concepción del imaginario individual de Bachelard es trasladada al ámbito social por Castoriadis.

Ahora bien, la imagen creadora en Bachelard escapa de la causalidad así como en Castoriadis se expresa la no causalidad del fenómeno social, o del ser de lo social. Hay en Bachelard una dinámica inmediata de la imagen que le permite estar siempre renovándose, así como hay un dinamismo de lo social-histórico en Castoriadis.

Este es, precisamente, un aspecto central en ese replanteamiento de la cuestión que intenta Castoriadis, ya que lo que denomina el pensamiento heredado ha escindido lo psíquico de lo social-histórico, imposibilitando una visión dinámica de ambos, como momentos fundantes, cooriginarios y recursivos tanto lógica como antológicamente. (Jiménez 2006: 37)

Lo imaginario en Castoriadis no es simplemente otra forma de nombrar las "representaciones sociales". Es una apuesta filosófica crucial por dilucidar aquel aspecto de lo social e histórico que lo distingue de otras regiones del ser, de otras formas ontológicas. 
Aquello que hace de lo social un ser que se crea a sí mismo y está en constante cambio. Como el imaginario y la imagen creadora en Bachelard, que está siempre renovándose. Lo imaginario surge en ambos como algo inexplicable bajo la lógica formal. Escapa de esta posible lectura.

Lo imaginario en Castoriadis está destinado a hacer pensable eso que la lógica y la ontología heredada o tradicional no ha podido pensar o ha pensado limitada y parcialmente. Está destinado a descubrir, por así decir, aquello que hace de lo social un ser extraño e inasible.

\begin{abstract}
lo social tampoco puede ser pensado con la lógica heredada, lo que quiere decir que no puede pensarse como unidad de una pluralidad en el sentido habitual de estos términos, o como conjunto determinable de elementos perfectamente distintos y bien definidos. Se ha de pensar con la imagen de magma, e incluso como magma de magmas, lo que no debe entenderse como caos, sino como el modo de organización de una diversidad no susceptible de ser reunida en un conjunto, ejemplificada por lo social, lo imaginario y lo inconsciente. (Castoriadis citado por Jiménez 1989: 34)
\end{abstract}

Según Castoriadis, lo social se presenta, tradicionalmente, como un conjunto formado de personas, cosas e ideas. Elementos que tienen entre sí determinadas relaciones. Esas relaciones no son otras que las que ha fijado la lógica formal desde Aristóteles en adelante, según Castoriadis.

La lógica “conjuntista identitaria” o lógica “ensídica”, cuya existencia es la determinación, es, según el autor greco-francés, el principal obstáculo para entender la naturaleza profunda del fenómeno social. Y el fenómeno social en Castoriadis tiene como particularidad esencial la de ser un ser que se crea a sí mismo creando sus propios elementos y sus propias relaciones. La "remisión" de significaciones a la que se refiere Castoriadis la podríamos relacionar con la resonancia y la repercusión a la que se refiere Bachelard, en el sentido de que estas otorgan el significado ontológico de una fenomenología del alma, que logra hacer percibir la sonoridad del ser de la imagen re-remitida. El principio de "remisión" de Castoriadis consistiría en que "toda significación remite a un número indefinido de otras remisiones".

En Castoriadis, hay 3 niveles de la realidad imaginaria: primero, el determinado; segundo, las significaciones imaginarias y tercero, la representación social. En Bachelard, lo imaginario es la matriz que produce imágenes, la matriz de creación. Y Bachelard la desarrolla, no la limita al ámbito pictórico, etc.

Los elementos y relaciones que forman lo social no están dados de una vez y para siempre, para Castoriadis. Y además de estas relaciones existe aquello que los hace ser, que les da existencia: el motor y formante de lo social, "lo instituyente", lo que se forma, lo que adquiere ser.

Cómo cobra ser el imaginario social es a lo que se refiere Castoriadis en su crítica a la ontología tradicional, así como Bachelard intenta establecer cómo cobra ser el imaginario creador. Recordemos que la imagen poética es variable y no constitutiva como el concepto según Bachelard, y esta cobra ser en el alma o psique de quien la crea para resonar, ser sentida, vivida y re-creada en otras almas. Se postula una actividad psíquica que produce imágenes. Hay un dinamismo del imaginario que cobra especial sentido en relación con Castoriadis.

Castoriadis procede a redefinir la psyque como la capacidad de imaginar, de producir imágenes o representaciones. Recordemos que lo usual había sido asignar ese papel exclusivamente a la imaginación, de tal modo que la filosofía asumió, desde Platón y Aristóteles, que esa era su capacidad privativa. Superar el modelo de la mecánica de las facultades ha conllevado, en este caso, a postular la entera actividad psíquica como producción de imágenes: la psique es ella misma emergencia de representaciones acompañadas de un afecto e insertas en un proceso intencional (Jiménez 2006: 40) 
Ahora bien, para Castoriadis, la imaginación es la creación humana indeterminada, por tanto, cambio. El cambio social implica discontinuidades radicales que no pueden ser explicadas en término de causas deterministas o presentadas como una secuencia de acontecimientos. El cambio emerge a través del imaginario social. Todas las sociedades construyen sus propios imaginarios: instituciones, leyes, tradiciones, creencias y comportamientos. Lo que distingue y diferencia al ser social de otros seres es eso que lo hace capaz de crearse y recrearse. Es posible que las "cosas" sean enteramente conjuntistas identitarias, pero la sociedad no lo es. Castoriadis nos habla de creación. No se puede ocultar el dato ontológico fundamental: de que en el ser hay creación. Dato ontológico ya presentado por Bachelard en relación con la imagen creadora y el imaginario. Es decir, lo social (el imaginario social) es un tipo de ser, una región ontológica específica, irreductible a cualquier otra región, y definible en lo esencial por su capacidad creadora.

La ontología directa de la imagen creadora en Gastón Bachelard y la ontología específica, irreductible y definible en lo esencial por su capacidad creadora en Castoriadis, podrían relacionarse y establecer un paralelismo entre ambas concepciones en lo ontológico, pero llevado por Castoriadis al ámbito del fenómeno social, en el dominio histórico social. Podríamos atrevernos a afirmar que, de alguna manera, el principio de lo imaginario en Bachelard, trasladado al plano de lo histórico-social, coincide con el del imaginario social en Castoriadis.

El imaginario es independiente de las voluntades particulares, este es creado, cobra ser y se hace manifiesto de una manera casi inefable. El imaginario, según Castoriadis, trasciende las voluntades y facultades lógicas tradicionales para "ser". Lo imaginario, de esta manera, incide, finalmente en las grandes transformaciones de la sociedad.

\section{Bibliografía}

Bachelard, Gaston. 1965a. El aire y los sueños. México D.F.:Fondo de Cultura Económica.

1965b. La poética del espacio. México D.F.: Fondo de Cultura Económica.

Campos, Jeannette. 2003. "La ontología directa de la imagen poética en Gastón Bachelard”. Revista Espiga. 7 (7): 35-46.

Castoriadis, Cornelius. 1988. Los Dominios del Hombre: las encrucijadas del laberinto. Barcelona: Gedisa.

1989. La Institución imaginaria de la Sociedad. Vol.2: El Imaginario Social y la Institución. Barcelona: Tusquets.

Jiménez, Jorge. 2006. "Filosofía de Ciudades imaginarias. Castoriadis: el imaginario instituyente". Revista de Filosofía de la Universidad de Costa Rica. 44 (113).

Jung, Carl G. 1974. El hombre y sus símbolos. Madrid: Editorial Aguilar. 
